\title{
120. Partial Trisomy 3q22 Involving the No. 15 Short Arm without Association with Cornelia de Lange Syndrome
}

\author{
By Tetsuji Kadotani,*) Yoko Watanabe,*) Takako Kryuna,*) \\ Toshimi KaWAMoto,*) Takashi Katano,**) \\ and Ichiro TAKEMURA***) \\ (Communicated by Sajiro Makino, M. J. A., Dec. 12, 1980)
}

Current banding chromosome analyses have rendered possible to reveal partial trisomy translocated on the other chromosome.

Previously we had an opportunity to report a case with a long arm duplication of chromosome no. 3, sporadic in occurrence (Kadotani et al. 1979). In the present article is reported a new case involving an abnormal chromosome no. 15 which carries a translocated portion of the long arm (3q22). Conclusively the aberration here concerned was defined as partial trisomy $3 q$ of maternal origin.

Case reports. The propositus was a one-year and two-month-old female baby, $8 \mathrm{~kg}$ in weight, with circumferences of $41 \mathrm{~cm}$ in head, and $71 \mathrm{~cm}$ in length. She was born to a 33-year-old mother and a 34year-old father as a second child. There was no history of abortion, still birth, congenital malformations, and consanguinity in this couple. Her mother was one of the atomic bomb survivous exposed in Hiroshima. Clinical examinations revealed that her parents and elder sister were phenotypically normal. The birth weight of this patient was $2820 \mathrm{~g}$ at 41 weeks gestation. The growth retardation as well as physical and mental development of this child were specially outstanding (Fig. 1). Remarkable clinical signs of this child were as follows: Brachycephaly, short neck, round face, hypertelorism, inverted epicanthus, congenital glaucoma at both eyes, saddle nose, high arched palate, wide-set nipples, hyperextensible hip in both sides, disturbance of gaits due to underdevelopment of the motor nerve, and mental deficiency.

Cytological findings. Chromosome slides for study were prepared from leucocyte cultures established from the propositus and her parents. For differential staining, the G- and Q-banding procedures

*) The Kadotani Medical Research Foundation. 1248, Saijohigashi, Saijo, Higashihiroshima, Hiroshima, Japan.

**) The Hiroshima City Welfare Center for the Handicapped Children. Hikarimachi, Hiroshima, Japan.

***) The Kojika-Gakuen. Awayacho, Miyoshi, Hiroshima, Japan. 
were applied to the slides made by the air-drying procedure. Chromosome counts were done with 50 well-delineated metaphases in each. Karyotypes were analysed in 20 cells each from conventional, G- and Q-banding preparations.



Fig. 1. A-C: External pictures of the propositus.

The karyotype of the proband derived from the conventional Giemsa specimens showed 46 chromosomes in which a no. 15 chromosome had an unusually elongated satellite on its short arm. The assessment of the unusual element became possible by the examinations of the maternal karyotype. The results of the examinations in the parents indicated that the mother was the balanced carrier of insertion of a long arm segment of no. 3 into the terminal portion of the satellite of no. 15 chromosome. The G- and Q-banding analyses made it possible to reveal that the segment q22 of chromosome no. 3 was missing, and that the missing segment was inserted into the terminal portion of the satellite of chromosome no. 15. Then, the chromosomal formula of the mother was designated as 46,XX,ins(15;3)(p13;q22) (Figs. 2, 3).

On the basis of the findings of the maternal translocation, it became evident that the aberration occurring in the propositus corresponds to partial trisomy for the long arm of no. 3. Then, her chromosomal formula was represented by 46,XX,der (15), ins (15;3) (p13; q22) mat (Fig. 4).

The father and the elder sister of the propositus were apparently normal in their karyotypes without showing any detectable chromosome change. 
Remarks and conclusion. Several cases of partial trisomy shown by $3 q$ have been announced with the discussion involving the correlation to Cornelia de Lange syndrome (Allderdice et al. 1975; Boue et al. 1974 ; Centerwall et al. 1977; Chiyo et al. 1976; Falek et al. 1966 ;
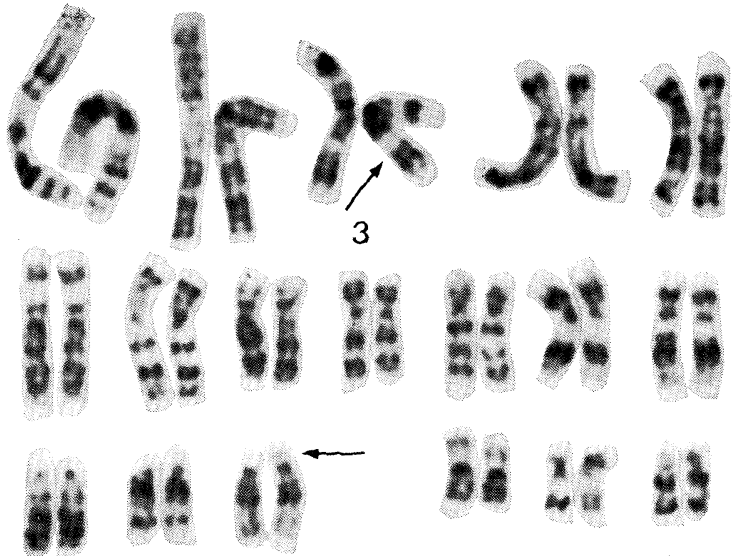

15

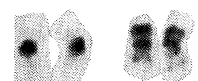

A
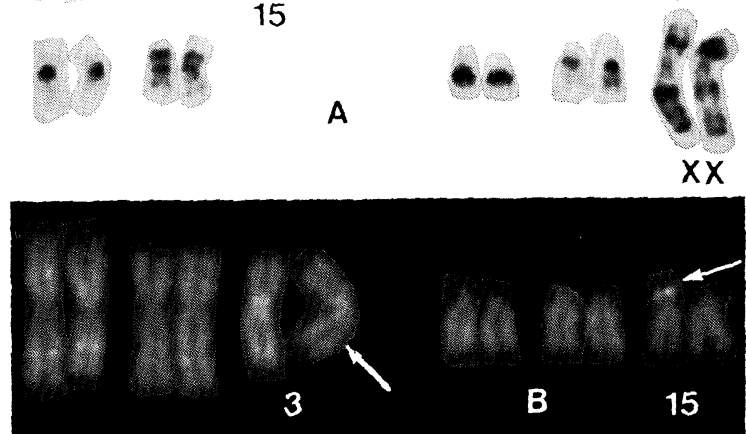

Fig. 2. G-(A) and partial Q-banding karyotype (B) of the mother, showing 46,XX,ins(15;3)(p13;q22). Balanced condition.
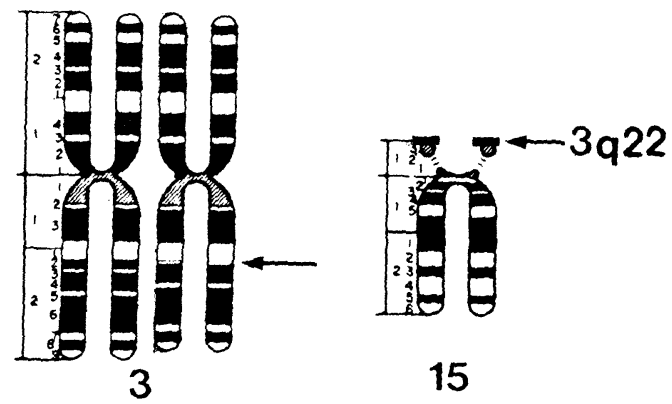

Fig. 3. Diagrams showing insertion of no. 3 long arm into the terminal portion of the satellite of chromosome 15. Balanced condition in mother. 
[Vol. 56(B),

Fear and Briggs 1979; Fineman et al. 1978; Fryns et al. 1978; Kadotani et al. 1979; Kondo et al. 1979; Mulcahy et al. 1979; Patil et al.

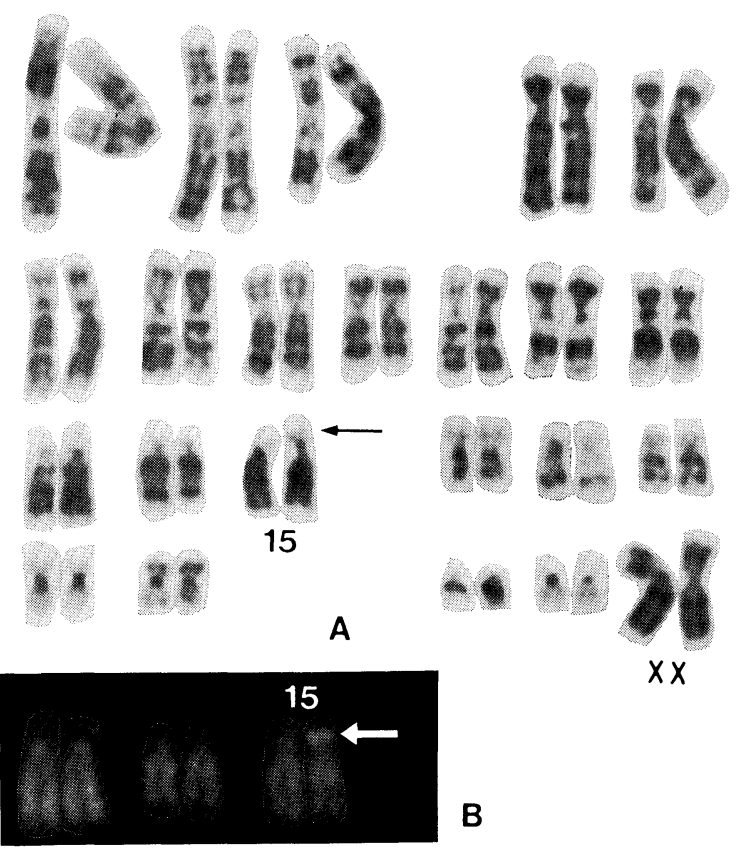

Fig. 4. G-(A) and partial Q-banding karyotype (B) of the propositus showing $46, \mathrm{XX}, \operatorname{der}(15)$,ins(15;3)(p13;q22)mat.

1978; Salazar et al. 1978; Sciorra et al. 1977; Schwanitz et al. 1977; Sod et al. 1978; Stengel-Rutkowski et al. 1979; Wilson et al. 1978; Yunis et al. 1979). It has been shown that the clinical pictures of the trisomic anomalies of $3 q$ are generally associated with the size and site of the trisomic segment.

The cases of trisomy of $3 q$ described prior to our case were remarkable by having a relatively long segment of the long arm of no. 3. In contrast, the $3 q$ of our case corresponded to a single short segment of no. 3, or 3q22.

The major clinical features of this case were mental retardation, glaucoma, inverted epicanthus and brachycephaly, without showing the signs of typical Cornelia de Lange syndrome. The mother of the proband is most probably a carrier of the balanced translocation involving the middle segment of a long arm of the no. 3 (q22) and the short arm of the no. 15 (Figs. 2, 3). She had one normal girl. The chromosome aberration of the propositus could be accounted for as the result of the gametic segregation of the abnormal no. 15 chromosome, leading to a partially trisomic for the long arm of a no. 3 chromosome. 
The conclusion is then possible that the propositus is characterized by the karyotype, 46,XX,der (15), ins (15;3) (p13;q22) mat, and that her mother is a carrier of the balanced translocation, 46,XX,ins $(15 ; 3)(p 13 ; q 22)$. This aberration is the first to be reported in man.

Acknowledgements. We are cordially obliged to Emeritus Professor Sajiro Makino, M. J. A., the senior consultant of the Kadotani Medical Research Foundation, for improvement of this manuscript with critical consideration, and also to Mrs. Yasuko Nakamoto and Mrs. Keiko Sasaki for their technical assistance. Financial aid from the Japan Academy is gratefully acknowledged here.

\section{References}

Allderdice, P. W., Browne, N., and Murphy, D. P. (1975) : Chromosome 3 duplication $q 21 \rightarrow$ qter deletion $\mathrm{p} 25 \rightarrow$ pter syndrome in children of carriers of a pericentric inversion inv (3) (p25q21). Am. J. Hum. Genet., 27, 699-718.

Boue, J., Hirshhorn, K., Lucas, M., Moszer, M., and Bach, C. (1974) : Aneusomies de recombinaison. Conséquences d'une inversion péricentrique d'un chromosome 3 paternel. Ann. Pédiat., 21, 567-573.

Centerwall, W. R., Pehl, C. A., and Merritt, W. H. (1977) : Distal 3q trisomy in an abnormal child. Am. J. Hum. Genet., 28, 28A.

Chiyo, H., Kuroki, Y., Matsui, I., Niitsu, N., and Nakagome, Y. (1976) : A case of partial trisomy 3q. J. Med. Genet., 13, 525-528.

Falek, A., Schmidt, R., and Jervis, G. A. (1966): Familial de Lange syndrome with chromosomal abnormalities. Pediatrics, 37, 92-101.

Fear, C., and Briggs, A. (1979): Familial partial trisomy of the long arm of chromosome 3 (3q). Arch. Dis. Child., 54, 135-138.

Fineman, R. M., Hecht, F., Ablow, R. C., Howard, R. O., and Breg, W. R. (1978) : Chromosome 3 duplication q/deletion p syndrome. Pediatrics, 61, 611-618.

Fryns, J. P., Van Eygen, M., Logghe, N., and Van Den Berghe, H. (1978) : Partial trisomy for the long arm of chromosome $3\{3(\mathrm{q} 21 \rightarrow \mathrm{qter})+\}$ in a newborn with minor physical stigmata. Hum. Genet., 40, 333-339.

Kadotani, T., Watanabe, Y., Kiyuna, T., Kawamoto, T., Takemura, I., and Funatsu, M. (1979) : A case with a long arm duplication of the no. 3 chromosome. Proc. Japan Acad., 55 B, 431-435.

Kondo, I., Hirano, T., Hamaguchi, H., Ohta, Y., Haibara, S., Nakai, H., and Takita, H. (1979) : A case of trisomy 3q21 $\rightarrow$ qter syndrome. Hum. Genet., 46, 141-147.

Mulcahy, M. Th., Pemberton, P. J., and Sprague, P. (1979): Trisomy 3q: Two clinically similar but cytogenetically different cases. |Ann. Génétique, 22, 217220.

Patil, S., Hanson, J., and Zellweger, H. (1978): Duplication-deletion of chromosome 3 syndrome. Am. J. Hum. Genet., 30, 89A.

Salazar, D., Rosenfeld, W., Jhaveri, R. C., Verma, R. S., and Dosik, H. (1978) : Partial trisomy for chromosome $3(3 q 12 \rightarrow q$ ter $)$ due to $3 q / 18 p$ translocation. Am. J. Hum. Genet., 30, 66A.

Sciorra, L. J., Coppola, P. J., and McCormack, M. K. (1977) : A new chromosome aberration and partial trisomy. Am. J. Hum. Genet., 29, 95A.

Schwanitz, G., Schmid, R. D., Grosse, G., and Grahn-Liebe, E. (1977) : Familial translocation 3/22 mat with partial trisomy 3q. J. Génét. Hum., 25, 141-150. 
Sod, R., Giorgiutti, E., Matayshi, T., de Kohan Gelman, Z., and Munoz, E. (1978) : Familial transmission of a $3 q ; 22 p$ translocation, with partial trisomy of chromosome 3 in the propositus. J. Génét. Hum., 26, 173-176.

Stengel-Rutkowski, S., Murken, J. D., Pilar, V., Dutrillaux, B., Rodewald, A., Goebel, R., and Bassermann, R. (1979) : New chromosomal dysmorphic syndromes. 3. Partial trisomy 3q. Eur. J. Pediatr., 130, 111-125.

Wilson, G. N., Hieber, V. C., and Schmickel, R. D. (1978): The association of chromosome 3 duplication and the Cornelia de Lange syndrome. J. Pediatr., 93, $783-788$.

Yunis, E., Quintero, J., Casteneda, A., Ramirez, E., and Leibovici, M. (1979) : Partial trisomy 3q. Hum. Genet., 48, 315-320. 